\title{
Descrição de Algumas Variáveis em um Procedimento de Supervisão de Terapia Analítica do Comportamento
}

\author{
Sandra Bernadete da Silva Moreira ${ }^{1} 2$ \\ Universidade Federal do Pará
}

\begin{abstract}
Resumo
Neste trabalho foi realizado um estudo descritivo da interação verbal livre e contínua entre um supervisor de terapia e um terapeuta iniciante, com o objetivo de identificar variáveis envolvidas no procedimento de supervisão adotado. O comportamento verbal dos participantes foi dividido em classes funcionais de respostas, denominadas "categorias de verbalizações", a partir das quais todas as respostas vocais puderam ser classificadas. Os resultados mostraram uma regularidade no comportamento do supervisor, enquanto os comportamentos do terapeuta e do cliente apresentaram alterações ao longo dos encontros de supervisões e das sessões terapêuticas. A análise da interação verbal livre em uma díade permitiu fazer inferências acerca de algumas variáveis de controle neste tipo de interação.

Palavras-chave: Supervisão de terapia; terapia comportamental; interação verbal; relato verbal; categorias de verbalizações.
\end{abstract}

\section{Description of Some Variables in a Behavior Analytic Therapy Supervision Procedure}

\begin{abstract}
In this work an analysis of a free, ongoing verbal interaction between therapy supervisor and a beginning therapist was carried out aiming to identify variables involved in the supervision procedure adopted. The participant's verbal behavior was divided into functional classes of responses, named "verbalizations categories", from which all vocal responses could be classified. The results showed a regularity in the supervisor verbal behavior, while the therapist's and client's behavior showed changes along supervision meetings and therapy sessions. The analysis of a free verbal interaction in a dyad allowed to make inferences about some controlling variables in this sort of interaction.

Keywords: Therapy supervision; behavior therapy; verbal interaction; verbal report; categories of verbalizations.
\end{abstract}

A supervisão da prática clínica psicológica é a etapa culminante do treino de terapeutas, sendo considerada indispensável na formação de psicólogos clínicos. Segundo Edelstein e Brasted (1991) desde quando foi formada a seção clínica na APA, em 1919, os psicólogos vêm se preocupando com a questão da formação e do treino para a futura prática em psicologia clínica. Já em 1924, a seção clínica da APA recomendava que os psicólogos clínicos tivessem pelo menos um ano de prática supervisionada e residência em psicologia (Edelstein \& Brasted, 1991).

De acordo com Robiner, Saltzman, Hoberman e Schirvar (1997), a atividade de supervisão está se tornando muito freqüente entre os psicólogos e é considerada uma habilidade essencial dos profissionais. De uma maneira geral, os principais objetivos da supervisão são fortalecer o

\footnotetext{
Agradecimentos:

Ao Prof. Dr. Roberto Alves Banaco, do Programa de Estudos PósGraduados em Psicologia Experimental: Análise do Comportamento, da PUC-SP, orientador da Dissertação de Mestrado que deu origem ao presente texto; e ao Prof. Dr. Olavo de Faria Galvão, do Programa de Pós-Graduação em Teoria e Pesquisa do Comportamento, da Universidade Federal do Pará, pela revisão do presente texto.

${ }^{2}$ Endereço para correspondência: Tv. Pirajá, 716, Bloco B, Ap. 501, 66087490. Bairro da Pedreira, Belém, Pará. Telefone: (91) 276-8180. E-mail: smoreira@ufpa.br
}

embasamento teórico, estabelecer uma conduta ética, e garantir a capacidade clínica. No entanto, o que exatamente torna a supervisão efetiva ou boa é algo que ainda não foi demonstrado com precisão.

Os critérios da APA para autorização do exercício da psicologia clínica requerem que as instituições de treino incluam prática supervisionada, porém apenas recentemente começaram as discussões acerca de um treino em teoria e métodos de supervisão (Robiner \& cols., 1997). A discussão acerca de uma metodologia padrão para o treino de terapeutas está apenas se iniciando.

Embora seja uma atividade utilizada com freqüência pelos psicólogos clínicos, não existe uma padronização de procedimentos de supervisão, o que leva a uma diversidade de metodologias ocasionada por diversos fatores, entre os quais a linha teórica e formação pessoal do supervisor, o ambiente onde é realizada a supervisão, questões burocráticas e institucionais, ausência de avaliação da prática da supervisão e ausência de modelos devidamente pesquisados. Mas é principalmente a falta de pesquisas no campo da supervisão clínica que faz com que cada supervisor utilize a metodologia que julga mais conveniente, tornando sua atividade inacessível à comunidade científica (Campos, 1989). 
$\mathrm{Na}$ literatura sobre pesquisa em terapia comportamental existem poucos estudos voltados para os procedimentos de treino de terapeutas comportamentais. Follete e Callagham (1995) analisando alguns estudos sobre o processo de supervisão, observaram que não há dados empíricos sobre como e o que deve ser treinado no processo de supervisão, ou se a supervisão realmente afeta o comportamento do supervisionado na sessão terapêutica.

Segundo Ellis, Ladany, Krengel e Schult (1996) é necessário conduzir pesquisas sobre a atividade de supervisão de terapia comportamental, principalmente para testar e aprimorar a teoria e oferecer guias para a atividade, fortalecendo a teoria analítico-comportamental.

Dentro da área da teoria do comportamento a visão mais freqüente é a que defende que o treino deveria ser voltado para formar analistas de comportamento, não somente terapeutas comportamentais, funcionando em um contexto de ensino-aprendizagem, ou seja, a atividade de supervisão é um processo de ensino-aprendizagem. A supervisão de terapeutas comportamentais é reconhecida como um meio chave pelo qual as habilidades são ensinadas, aprendidas e refinadas (Campos, 1989). Nesse sentido, o processo deve levar a uma mudança no comportamento do terapeuta que possa ser observada e avaliada.

Mesmo entre terapeutas que compartilham o mesmo embasamento teórico, da análise aplicada do comportamento, não existe um consenso sobre o que deve ser ensinado e como deve ser o treino em terapia comportamental. Na maior parte das situações de supervisão, a atividade do supervisor é baseada na sua própria experiência, na sua formação e no seu treino (Campos, 1994).

O processo de supervisão de terapia pode ser realizado por meios diversos, tais como, relatos da sessão terapêutica feitos pelo supervisionado, observação direta da sessão terapêutica através de espelhos unidirecionais onde o supervisor pode usar sistemas de ponto auditivo ou encontrar-se com o supervisionado em um momento posterior, participação direta do supervisor na sessão terapêutica estando presente na sala, enfim, uma série de métodos podem e são utilizados pelos supervisores.

A supervisão baseada no relato verbal ainda é o meio mais comumente utilizado no treino. O supervisor ouve o relato do terapeuta sobre os acontecimentos da sessão terapêutica analisa o comportamento do terapeuta e dá as orientações devidas. Alguns autores apontam limites nos estudos baseados em relatos verbais, principalmente com relação à veracidade do relato e muitos outros fatores que interferem nesse relato (Barker, Pistrang \& Elliot, 1994; De Rose, 1997)
As principais desvantagens observadas pelos terapeutas em treino dizem respeito ao fato de seu próprio processo de autodiscriminação tornar-se mais demorado. De Rose (1997) aponta para o fato de que para relatar o próprio comportamento é necessária a instalação do comportamento de auto-observação, o qual nem sempre acompanha o comportamento a ser relatado. Este fato consiste em uma nova etapa no treino. O terapeuta precisa então de um tempo maior para conseguir observar seu próprio comportamento, identificar variáveis controladoras, descrever com uma certa veracidade, para, enfim, promover qualquer mudança.

A supervisão com base na observação direta da relação terapêutica é utilizada com menor freqüência apesar da teoria analítica do comportamento enfatizar que a observação é o meio mais indicado para se realizar uma análise objetiva de uma condição. Nesta forma, o supervisor pode interagir com o terapeuta através de um sistema de ponto auditivo, indicando formas de comportamento, ou fazer anotações sobre a interação terapêutica para em um momento posterior discuti-las no encontro direto com o terapeuta.

Banaco e Zamignani (1999), destacaram que não é suficiente observar a interação entre terapeuta e cliente, mas é necessário manter um contato direto com o terapeuta para que ele tome conhecimento dos aspectos considerados relevantes pelo supervisor, bem como para que ele próprio possa formular novas formas de comportamento.

A despeito das diferenças entre os procedimentos utilizados em supervisão de terapia, os resultados mostram que a supervisão torna mais rápido o processo de discriminação, por parte do terapeuta, dos controles sobre seu comportamento na sessão terapêutica. Porém, há uma ausência, na literatura sobre supervisão de terapia de base analítica do comportamento, de estudos descrevendo as variáveis envolvidas no processo de supervisão. $\mathrm{O}$ que o supervisor faz e como ele faz ainda são fatos obscuros dentro da teoria.

O objetivo deste estudo foi o de tentar identificar e descrever algumas variáveis presentes em um procedimento de supervisão de terapia de base analítica do comportamento, especificamente o que o supervisor faz, como ele faz e quais mudanças ocorrem no comportamento do terapeuta.

O procedimento para análise do comportamento verbal teve como base o trabalho de Drash e Tudor (1991) cujo sistema dividiu todo o comportamento verbal em classes funcionais de respostas, a partir das quais todas as respostas vocais dos sujeitos podiam ser classificadas e conseqüenciadas. Neste estudo os autores apresentam uma "solução parcial" para o que consideram um problema metodológico na pesquisa com comportamento verbal, a questão da variável 
dependente. O sistema que eles apresentaram incorpora a taxa de resposta e a probabilidade de resposta como variáveis dependentes básicas. O primeiro componente do sistema envolve o estabelecimento de quatro classes de respostas funcionais que podem dar conta de todo o comportamento verbal de um sujeito e o segundo componente incorpora a freqüência da resposta dentro de cada uma das categorias. Isto tornaria imediatamente visíveis os efeitos das mudanças nas contingências de reforçamento como mudanças na freqüência da resposta. Segundo os autores, a classificação de cada resposta vocal dentro de uma das quatro categorias de análise, permite ao pesquisador ou clínico aplicar imediatamente e contingentemente uma conseqüência pré-determinada para qualquer resposta vocal.

No presente estudo, o procedimento de registro do comportamento verbal consistiu da gravação em áudio e vídeo e posterior transcrição das sessões terapêuticas e dos encontros de supervisão, e da construção de um protocolo de análise destes registros, baseado em Greene e Bry (1991). Estes autores desenvolveram um sistema de codificação para analisar as relações entre os comportamentos verbais em discussões familiares para solução de problemas. O protocolo de codificação foi feito com os registros transcritos das conversas entre as pessoas da família, os quais foram divididos em verbalizações (grupos de palavras, frases) que foram categorizadas. O sistema de codificação utilizado pelos autores teve como base um exame indutivo das verbalizações nos registros, o que permitiu a construção de um manual de codificação que refletia acuradamente as topografias das verbalizações e incluía uma lista de categorias, uma descrição da faixa de verbalizações a serem codificadas dentro de uma categoria, palavras típicas e construções verbais, distinções entre categorias e um conjunto de regras de codificação.

\section{A Questão das Unidades sob Investigação no Estudo do Comportamento Verbal}

Questões metodológicas envolvidas na análise do comportamento verbal dizem respeito a como definir as unidades a serem investigadas, como os dados serão apresentados e que tipo de medida (freqüência, duração) será usado para assegurar a objetividade no processo analítico (Leigland, 1996).

No estudo do comportamento verbal, a noção de "unidade" é bastante complexa, pois uma grande variedade de unidades verbais pode ser definida funcionalmente. Em seu experimento, Leigland (1996) escolheu "tópico" como a unidade ou dimensão verbal, bem como outras expressões aproximadas do tópico. Para o autor, o termo "tópico" descreve uma dimensão complexa do comportamento verbal contínuo, mas cuja ocorrência é possível ser discriminada e identificada por observadores dentro de uma comunidade verbal. Em seu experimento, breves tons foram usados para modelar "tópicos" particulares no comportamento verbal de um falante em um contexto experimental. Tópicos pré selecionados foram escolhidos em diferentes arranjos experimentais.

No presente estudo, o procedimento de análise da interação verbal entre o supervisor e terapeuta e entre terapeuta e cliente, foi baseado em categorias de comportamento verbal, construídas a partir da análise do registro do próprio comportamento verbal dos participantes.

\section{Método}

\section{Participantes}

Os participantes foram 2 terapeutas comportamentais: o primeiro, com mais de quinze anos de profissão e de prática de supervisão clínica acadêmica, foi o supervisor neste estudo; o segundo, com menos de três anos de experiência clínica, foi o terapeuta-supervisionado.

\section{Procedimentos}

Todas as sessões terapêuticas foram filmadas, sendo que a câmera de VHS ficava dentro da sala de atendimento e o foco ficava voltado apenas para o terapeuta. O supervisor observava a sessão em uma sala contígua através de um espelho unidirecional.

Os encontros de supervisão eram realizados imediatamente após o término das sessões terapêuticas e eram gravadas através de um micro-cassete, manipulado pelo próprio supervisor. A sessão terapêutica subseqüente era realizada uma semana depois.

\section{Tratamento dos dados}

Foram analisadas sete sessões terapêuticas consecutivas e iniciais e seis encontros de supervisão relativos a essas sessões terapêuticas. Todos os registros das sessões terapêuticas e de supervisão foram transcritos pela pesquisadora.

Foram registradas as interações verbais livres e contínuas dos participantes e a análise foi baseada na classificação das respostas verbais de forma a permitir a identificação de contingências selecionadoras de verbalizações particulares.

A unidade de análise utilizada foi Categoria de Verbalização, cuja variação, de maneira ordenada, permitiu identificar operações de reforçamento e extinção em atividade. "Categoria" foi o termo descritivo mais preciso encontrado para identificar uma verbalização como uma unidade funcional, de maneira semelhante a um comportamento não verbal. Uma dada "categoria" é uma definição operacional de um dado tipo de verbalização. 
A classificação do comportamento verbal dos sujeitos nas categorias construídas foi ajustada com base na observação dos efeitos de contingências ambientais sobre tais categorias de verbalizações.

As interações verbais entre os falantes foram divididas em falas. Uma "fala" foi definida como uma série de verbalizações emitidas por um falante delimitadas pela fala anterior e fala subseqüente do outro falante. Para facilitar a categorização, as transcrições das falas foram digitadas novamente dividindo-se as falas em verbalizações, definidas como grupos de palavras dentro de uma fala, isolando-se as verbalizações categorizáveis em linhas separadas.

Para proceder à análise das interações verbais foi preparado um protocolo que consistiu na construção das categorias de verbalizações. Com base na primeira sessão terapêutica, foram definidas as unidades de comportamento do Terapeuta e do Cliente, totalizando 19 categorias de verbalizações para o terapeuta, e 14 para o Cliente. Da mesma forma, com base no primeiro encontro de supervisão, foram construídas 20 categorias para o supervisor e 14 para o terapeuta. As categorias de verbalizações foram computadas para o cálculo dos percentuais de freqüência de cada uma, por sessão terapêutica e por encontro de supervisão.

As 13 sessões transcritas foram categorizadas pelo autor e por três avaliadores independentes, alunos de pósgraduação no mesmo programa engajados em estudos semelhantes. O Observador 1 ficou responsável pela categorização de quatro sessões terapêuticas e duas sessões de supervisão; o Observador 2 ficou responsável pela categorização de três sessões terapêuticas; e o Observador 3 ficou responsável pela categorização de quatro sessões de supervisão. Os resultados das categorizações foram comparados e a concordância entre o autor e o Observador 1 foi $78 \%, 79 \%, 80 \%$ e $83 \%$, nas quatro sessões terapêuticas e $74 \%$ e $81 \%$ nas sessões de supervisão; a concordância entre o autor e o Observador 2 foi $87 \%, 80 \%$ e $80 \%$ nas três sessões terapêuticas; e finalmente, a concordância entre o autor e o Observador 3 foi $89 \%, 88 \%, 83 \%$ e $85 \%$ nas quatro sessões de supervisão.

A descrição com exemplificação das categorias de verbalizações do Supervisor e do Terapeuta, nos encontros de supervisão e do Terapeuta e do Cliente nas sessões terapêuticas, podem ser encontradas nos Anexos A a D.

\section{Resultados}

Na Figura 1 são apresentadas as porcentagens médias de cada categoria de verbalização do Supervisor ao longo dos encontros de supervisão. As verbalizações mais freqüentes na supervisão foram as que descreviam o comportamento do terapeuta na sessão terapêutica (DCT $=12 \%$ ) e as verbalizações que descreviam ou sugeriam comportamentos futuros ao Terapeuta, as quais foram denominadas de Regras Específicas (REGE $=12 \%$ ). O terceiro mais freqüente tipo de verbalizações foi descrições de relações entre o comportamento do terapeuta e o comportamento do cliente na sessão terapêutica $(\mathrm{RCO}=$

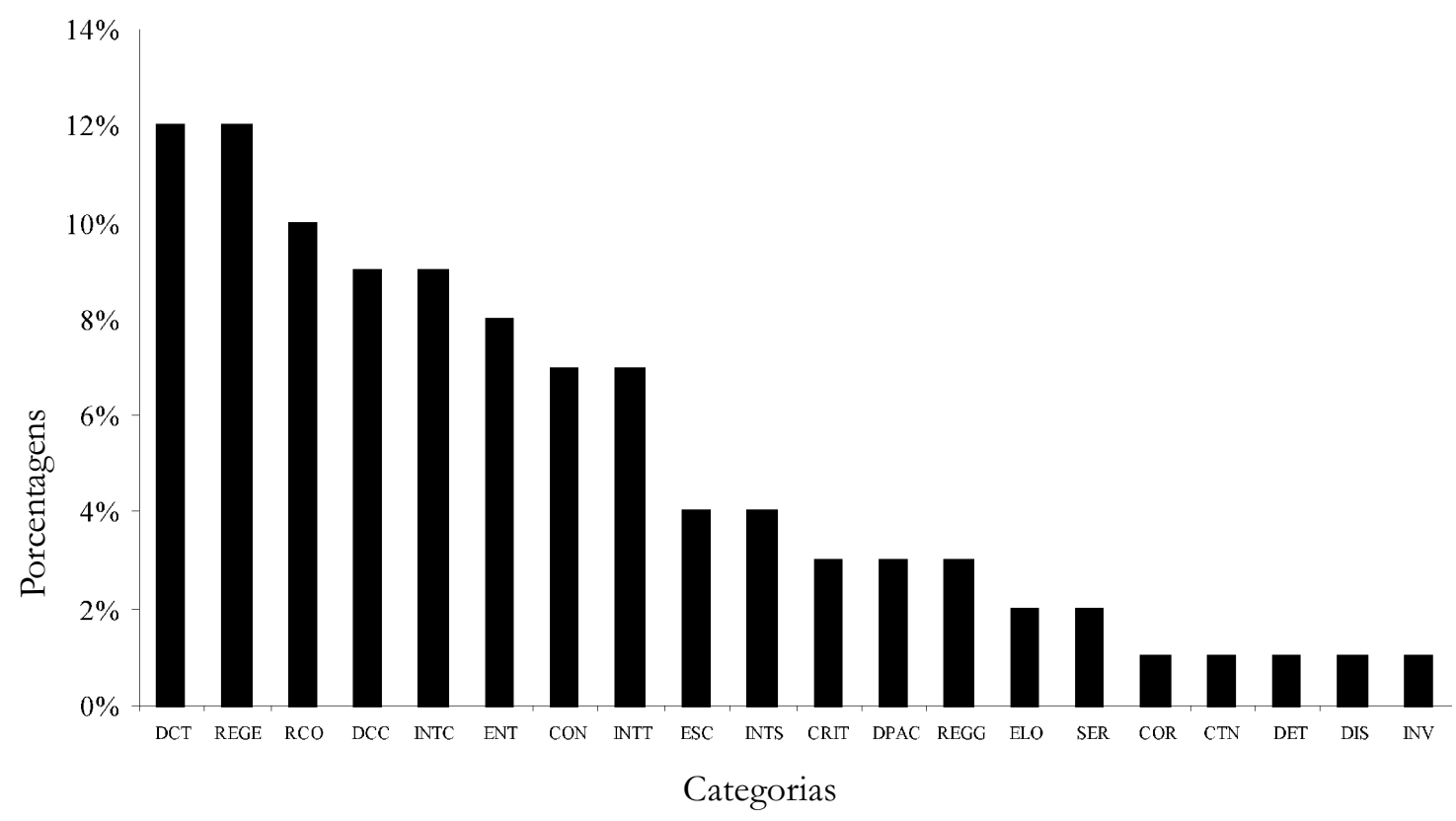

Figura 1. Porcentagens médias das freqüências de categorias de verbalizações do Supervisor. 
10\%) - ou dizendo de outra maneira, descrições da interação terapêutica. As categorias DCC (Descrição do Comportamento do Cliente) e INTC (Interpretação do Comportamento do Cliente) apresentaram $9 \%$ de freqüência. As afirmações de entendimento (ENT) obtiveram uma freqüência média de $8 \%$ e as afirmações de concordância (CON) e interpretações do comportamento do terapeuta (INTT) apresentaram uma média de $7 \%$ de freqüência. As demais categorias tiveram freqüência entre 1 e $4 \%$.

A Figura 2 mostra o percentual das categorias de verbalizações mais freqüentes apresentadas pelo Supervisor ao longo dos seis encontros de supervisão (DCT, REGE, RCO, DCC, INTC, ENT, CON, INTT, que apresentaram percentual de freqüência acima de $7 \%$ ).

Observa-se que houve uma diminuição na freqüência dos comportamentos de descrever o comportamento do terapeuta (DCT), que começou com uma freqüência $14 \%$ e na última supervisão registrou $10 \%$. E o comportamento de formular regras ao terapeuta (REGE) que também apareceu com uma freqüência de $14 \%$ no primeiro encontro, apresentou uma diminuição para 9 $\%$ no último encontro. Na última sessão de supervisão o comportamento mais freqüente do supervisor foi o de "Descrição do comportamento do cliente" (DCC) que havia apresentado uma freqüência de $6 \%$ na primeira supervisão. Esta figura também permite identificar um padrão diferente no comportamento do supervisor no quinto encontro de supervisão. Neste encontro, ao contrário dos demais, onde o supervisor podia ver e ouvir o que acontecia na sessão terapêutica, o supervisor ficou impedido de ouvir a interação verbal entre terapeuta e cliente por defeito no sistema de áudio da sala de observação. O comportamento mais freqüente apresentado pelo supervisor neste encontro foi "ENT" (verbalizações que expressam entendimento do relato do terapeuta, e que possuem a função de sugerir continuidade ao relato). Este padrão sugere que o comportamento do supervisor esteve mais controlado pelo relato do terapeuta, do que pelos aspectos observados na sessão. Observa-se também que um outro tipo de verbalização (INTT - Interpretações do comportamento do terapeuta) aparece com maior freqüência quando comparado às outras supervisões, sugerindo uma tentativa, por parte do supervisor, de entender e explicar o comportamento do terapeuta a partir de seu próprio relato. As verbalizações de descrição do comportamento do terapeuta (DCT) apresentaram uma queda na freqüência para 3\% neste encontro, o que sugere que o supervisor precisou ouvir mais o que o terapeuta tinha a dizer do que descrever.

Por meio da Figura 2, podemos inferir que o supervisor estava mais preocupado com o desempenho do terapeuta, visto que as freqüências das verbalizações que objetivavam explicar o comportamento do cliente (INTC) apresentaram uma tendência decrescente, principalmente a partir da segunda supervisão, na qual, este comportamento apresentou a maior freqüência, acompanhado de REGE (regras ao terapeuta).

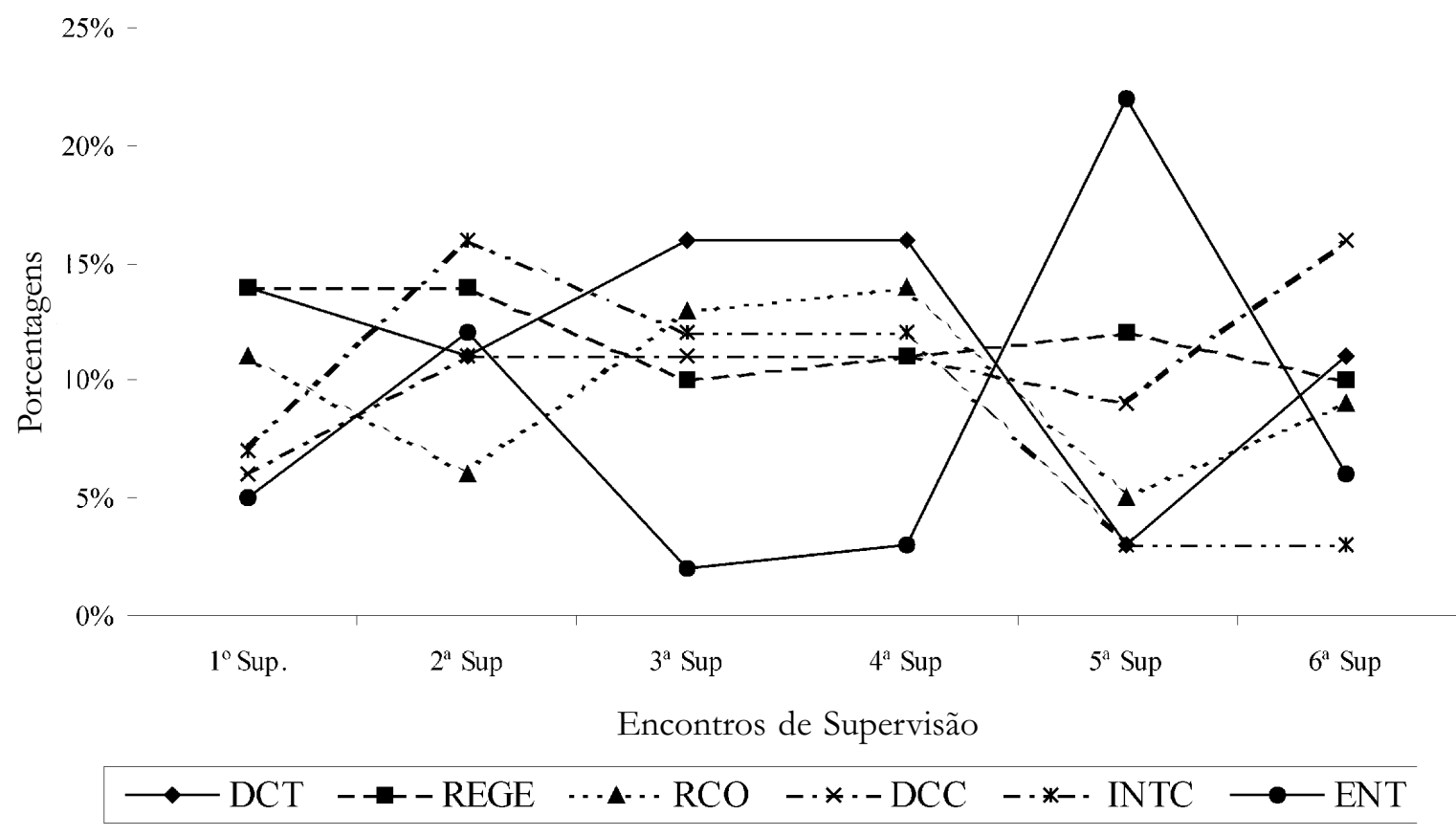

Figura 2. Porcentagens das categorias de verbalizações mais freqüentes do Supervisor. 
Este padrão sugere que o supervisor precisou explicar quais aspectos do comportamento do cliente estavam controlando o do terapeuta e sugerir a este formas de conduta futuras para evitar algumas situações dentro da sessão.

A Figura 3 mostra a porcentagem média das freqüências das categorias de verbalizações do terapeuta ao longo dos encontros de supervisão. A categoria de verbalização que apareceu com maior freqüência foi a de Descrições de seu Próprio Comportamento (TDPC $=22 \%$ ), seguida de Descrições do Comportamento do Cliente (TDCC $=15$ \%) e Verbalizações de Concordância (TCON - 15\%).

A Figura 4 mostra as freqüências das categorias de verbalizações do terapeuta que apareceram com maior freqüência (respectivamente TDPC, TDCC, TCON, TINC, TRCO e TINT), em cada encontro de supervisão.

A categoria TCON (Concordância com o relato do supervisor, expressando aceitação das explicações ou regras formuladas) é a segunda categoria que aparece com a freqüência mais elevada em todas as supervisões, com exceção do quinto encontro de supervisão, no qual a categoria mais freqüente foi aquela das verbalizações que descreviam o comportamento do cliente (TDCC). Descrever o seu próprio comportamento (TDPC) não controlou o comportamento do supervisor no quinto encontro, pois aparentemente este precisava obter detalhes sobre o que o cliente havia falado para poder proceder às suas análises e formulações de regras ao terapeuta. Assim observa-se, no quinto encontro de supervisão, um aumento das verbalizações que descreviam o comportamento do cliente (TDCC) e estabeleciam relações entre seu comportamento e o do cliente dentro da sessão terapêutica (TRCO) e uma diminuição nas verbalizações que descreviam seu próprio comportamento (TDPC) e que expressavam concordância e aceitação do relato do supervisor (TCON). Ressalte-se que TRCO (Estabelecer Relações entre seu Comportamento e o do Cliente) foi o que apareceu com a

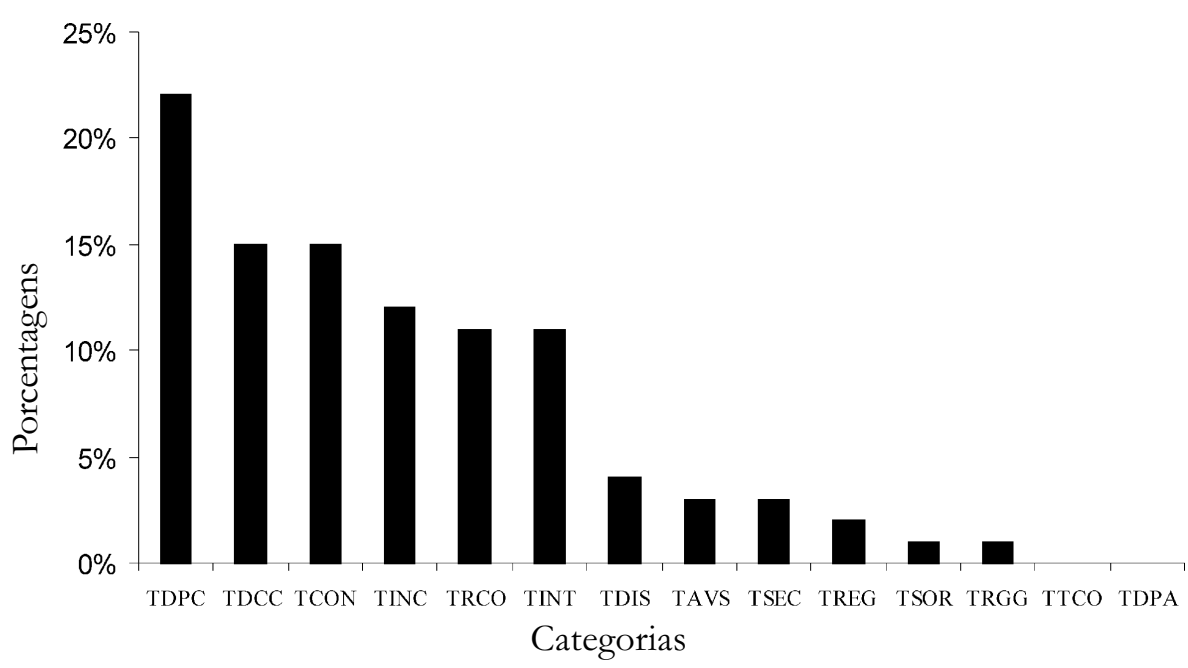

Figura 3. Porcentagens médias das categorias de verbalizações do Terapeuta.

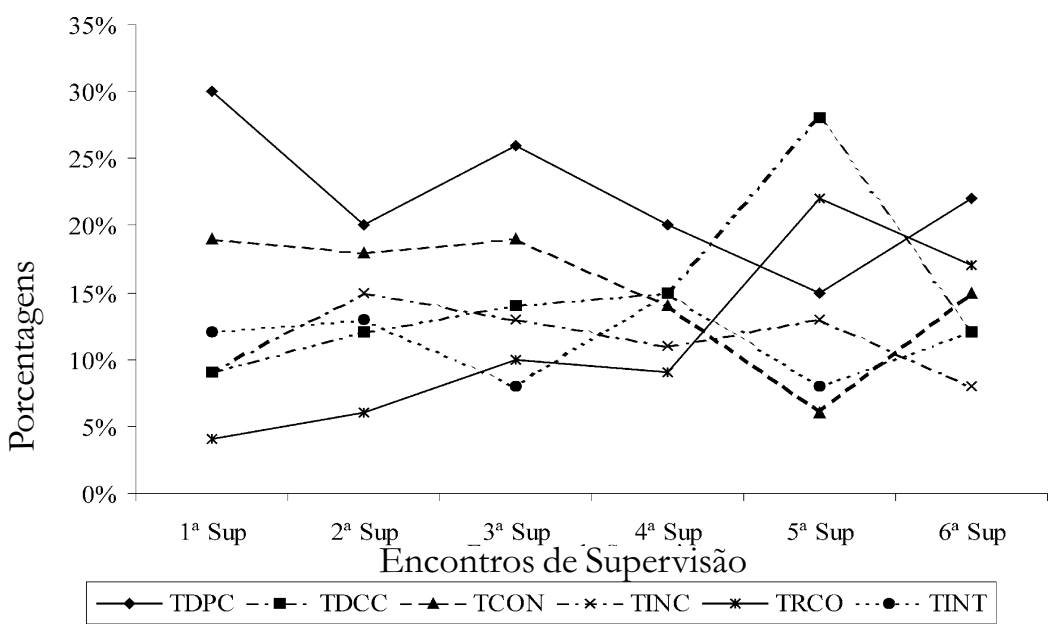

Figura 4. Porcentagem das categorias de verbalizações mais freqüentes do terapeuta nos encontros de supervisão. 
freqüência mais baixa no primeiro encontro de supervisão, vindo a acontecer com a segunda maior freqüência no último encontro. No último encontro de supervisão o comportamento verbal mais freqüente do terapeuta voltou a ser o de descrever seu próprio comportamento (TDPC) e o menos freqüente foi o de apresentar interpretações e análises sobre o comportamento do cliente (TINC)

Observa-se nas Figuras 2 e 4 que, no decorrer dos encontros de supervisão, o supervisor foi apresentando uma diminuição na freqüência do comportamento de Formular Regras (REGE, $14 \%$ no primeiro encontro e $10 \%$ no segundo). Ao mesmo tempo o terapeuta apresentou um aumento gradual no comportamento de identificar as relações entre seu comportamento e o do cliente (TRCO, de $4 \%$ no primeiro encontro para $16 \%$ no último). Podese inferir que à medida que o terapeuta aumentava a freqüência de estabelecimento de relações entre seu próprio comportamento e o comportamento do cliente, o supervisor diminuía a formulação de regras ou indicação de comportamentos futuros ao terapeuta na sua relação com o cliente.

A Figura 5 mostra as porcentagens das categorias de verbalizações mais freqüentes apresentadas pelo terapeuta nas sessões terapêuticas. Como pode ser observado, nas sessões iniciais o terapeuta apresentou uma freqüência relativamente alta do comportamento de solicitar ao cliente descrições de seu comportamento (TSDC $=22 \%$ ). Nas sessões finais houve um aumento na freqüência do comportamento de solicitar descrições do contexto do cliente, ou melhor, do ambiente onde o cliente se comportava (TSDO, de 3\% para 7\%). Paralelamente houve um aumento no comportamento de estabelecer relações entre o comportamento do cliente e o seu contexto (TSRE). Também houve um aumento na freqüência do comportamento de "Interpretar o Comportamento do Cliente" (TICC, $4 \%$ na primeira sessão terapêutica e $12 \%$ na última).

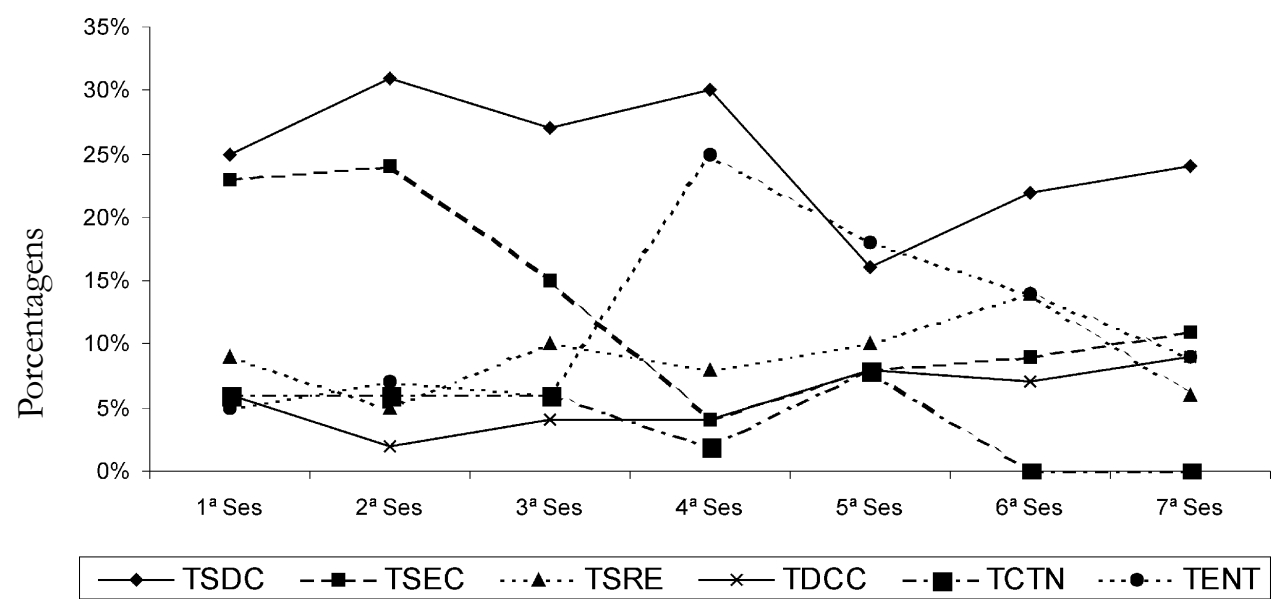

Figura 5. Porcentagens das categorias de verbalizações mais freqüentes do Terapeuta nas sessões terapêuticas.

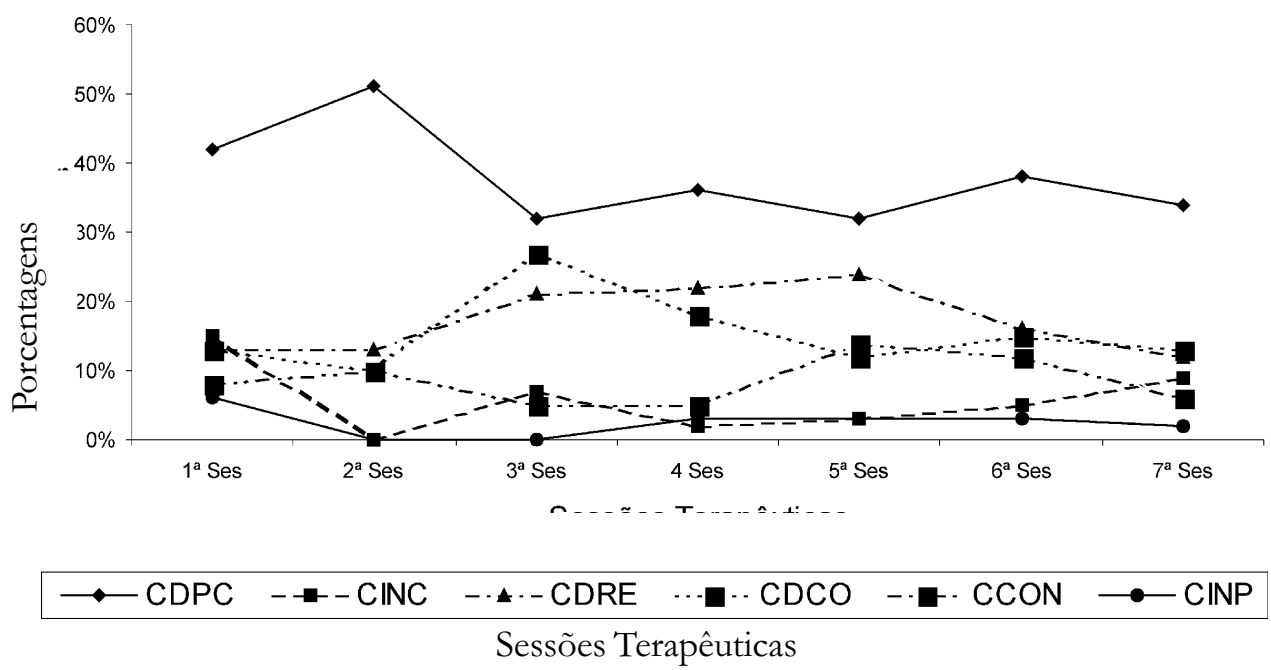

Figura 6. Porcentagens das categorias de verbalizações mais freqüentes do Cliente. 
O terapeuta passou a apresentar, nas sessões terapêuticas, um padrão de comportamento semelhante ao comportamento do supervisor nos encontros de supervisor. O supervisor descrevia o comportamento do terapeuta e formulava regras com alta freqüência ao longo de todos os encontros de supervisão, e este padrão passou a ser observado no comportamento do terapeuta nas sessões terapêuticas.

A Figura 6 mostra as porcentagens das categorias de verbalizações mais freqüentes apresentadas pelo cliente. As verbalizações mais freqüentes foram Descrever seu Próprio Comportamento (CDPC), Descrever Relações entre seu Comportamento e seu Ambiente (CDRE) e Descrições do Comportamento de Outras Pessoas (CDCO), embora com algumas oscilações ao longo das sessões terapêuticas. Pode-se observar, ainda, que houve um aumento nas verbalizações que solicitavam esclarecimentos ao terapeuta (CSEC), contudo, com uma freqüência abaixo de 10\%.

\section{Discussão}

Os resultados mostraram uma regularidade no comportamento do supervisor. No geral, ele descrevia o comportamento do terapeuta, descrevia o comportamento do cliente, estabelecia relações entre esses dois comportamentos, apresentava análises ou interpretações e fornecia sugestões de respostas futuras do terapeuta, as quais foram denominadas regras. Também o terapeuta passou a apresentar um aumento na freqüência de respostas de autoobservação e autodescrição, observado por meio das modificações nas categorias de verbalizações.

É importante apresentar uma breve análise acerca do procedimento de supervisão analisado neste estudo, que foi a observação direta do comportamento. Pode-se afirmar que o supervisor também esteve exposto às mesmas contingências que estavam controlando o comportamento do terapeuta, embora de forma parcial, já que ele não estava interagindo diretamente com o cliente, mas de maneira indireta ele estava sob a mesma condição de estimulação que o terapeuta. Essa observação direta da interação entre o terapeuta e seu cliente permitiu ao supervisor uma maior probabilidade de modelar e manter a discriminação do terapeuta das funções de estímulo que estavam controlando as suas respostas e como diferenciar as respostas.

Podemos supor que esse procedimento de supervisão tem maior probabilidade de instalar repertórios autodiscriminativos porque tanto o supervisor quanto o terapeuta tinham conhecimento das variáveis envolvidas os dois estavam presentes na situação, embora o supervisor apenas parcialmente. Assim, quando o supervisor apresentava uma análise ao terapeuta os dois tinham possibilidade de discutir melhor esta análise. O supervisor tinha a possibilidade de usar estímulos reforçadores em maior freqüência pois havia observado as contingências da sessão terapêutica no momento em que ocorriam. Nos outros procedimentos, por exemplo, quando o supervisor somente ouve o relato, apenas o terapeuta foi exposto às contingências. A observação direta e o feedback verbal dado imediatamente ao terapeuta auxiliaram na aceleração do processo de autodiscriminação e auto-regulação do terapeuta.

Por outro lado, com tal procedimento, o terapeuta tem menor responsabilidade no relato ao supervisor, o que deve resultar em freqüências diferentes das categorias de relato, como pode ser constatado pelo padrão resultante no quinto encontro de supervisão, cujo procedimento sofreu uma alteração em relação aos demais encontros. Ainda assim, pode-se inferir que este tipo de procedimento é válido para instalar repertório de autoobservação e autoconhecimento no terapeuta, posto que este era sempre induzido a analisar seu comportamento e apresentar novas formas de conduta frente ao seu cliente.

Segundo De Rose (1997) a auto-observação permite descrever o próprio comportamento e identificar as variáveis das quais ele é função, assim resultando em autoconhecimento e autocontrole. Barker, Pistrang e Elliot (1994), também apontam para a utilidade da observação externa como meio de aprimorar o relato em pesquisas que utilizam o relato verbal como fonte de informação.

Segundo Skinner (1969), em uma relação funcional há uma relação sistemática observada entre a variável independente e a variável dependente. Relações funcionais em interações verbais são difíceis de analisar porque o comportamento alvo ocorre em longas seqüências da interação verbal entre os dois falantes. No entanto, a forma de coleta e registro de dados, bem como a utilização de uma interação diádica, permitiu, neste estudo, observar comportamentos antecedentes e subseqüentes, e estabelecer a relação entre eles. As verbalizações destacadas foram consistentes e suas correlações e posições temporais sugerem relações funcionais.

As relações entre os comportamentos dos participantes dos episódios verbais analisados sugerem relações de controle, observadas principalmente quando o supervisor estabeleceu relações entre eventos ou apresentou uma análise, e o terapeuta concordou e apresentou, em seguida, mudanças em seu comportamento tanto nas sessões de supervisão quanto nas sessões terapêuticas.

O comportamento do supervisor de descrever eventos da sessão terapêutica pode ter funcionado como estímulo discriminativo para o comportamento de descrever o próprio comportamento do terapeuta. Assim como 
"concordâncias" podem ter funcionado como estímulos sociais reforçadores para ambos os falantes. As concordâncias do terapeuta podem ter funcionado como estímulos verbais reforçadores das descrições e interpretações do supervisor, com as quais apresentaram alta freqüência de relação de contigüidade. Greene e Bry (1991) citam que "concordâncias" também foram vistas como eventos reforçadores nos estudos de Greenspoon (1955), o qual mostrou que "concordâncias" através de verbalizações mínimas ("Hum, hum") aumentavam a freqüência de substantivos plurais, e em Place (1988) que mostrou que a continuação de interação verbal era uma função de concordâncias como conseqüência.

Por sua vez, as descrições e análises apresentadas pelo supervisor, transformadas em regras, podem ter funcionado como estímulos discriminativos governando comportamentos verbais adicionais do terapeuta, os quais, por sua vez, funcionaram como contingências reforçadoras para o supervisor continuar a apresenta-las.

\section{Considerações Finais}

Este estudo permitiu observar uma regularidade no comportamento verbal do supervisor, porém foram verificadas algumas mudanças no comportamento verbal do terapeuta, tanto nos encontros de supervisão quanto nas sessões terapêuticas. É possível inferir que tais mudanças foram uma função das solicitações verbais do supervisor e que portanto o comportamento verbal do terapeuta foi modelado pelo comportamento verbal do supervisor. E, além disso, que o procedimento de supervisão utilizado é válido para instalação de respostas de auto-observação, auto-descrição e auto-regulação no repertório comportamental do terapeuta.

Pesquisas sobre procedimentos de supervisão ainda são escassas na literatura da análise do comportamento. Nos estudos levantados (Banco \& Zamignani, 1999; Campos, 1989, 1994; Ellis \& cols., 1996; Follete \& Callaghan; 1995; Watkins, 1997), foi possível identificar pelo menos três formas de estudar procedimentos de supervisão. A primeira seria através de levantamentos feitos com supervisionados, sobre as características do supervisor (Watkins, 1997). Este autor relatou alguns estudos que levaram ao desenvolvimento de um tipo de "perfil do bom supervisor". Outra forma semelhante a esta se dá através de levantamentos junto ao supervisor sobre como procede ao treino de seus alunos (Campos, 1989, 1994). Uma terceira maneira identificada de analisar o processo de supervisão são os relatos de experiências (Banaco \& Zamignani, 1999; Follete \& Callaghan, 1995).

Psicologia: Reflexão e Crítica, 2003, 16(1), pp. 157-170
Constata-se uma ausência de orientações sistematizadas para a atuação de supervisores. Para Campos $(1989,1994)$ pouco se sabe sobre quais variáveis são relevantes no processo de supervisão. $\mathrm{Na}$ ausência de uma base de dados substantivos sobre métodos de supervisão torna-se difícil avaliar com objetividade a relação entre o processo de supervisão e a qualidade da prática do supervisionado.

A supervisão, como parte do treinamento de terapeutas, deve ser submetida a estudos rigorosos para que seja construída uma metodologia que sirva como base para o estabelecimento de critérios cientificamente apoiados de ensino e de avaliação do ensino.

O presente estudo serviu como uma tentativa de estudar a relação entre o ensino e a prática terapêutica através do registro e análise da interação entre o supervisor e o supervisionado, tentando identificar as mudanças ocorridas no repertório do terapeuta.

As categorias de verbalizações resultantes da análise do comportamento verbal do supervisor, do terapeuta e do cliente, fornecem uma base para o estudo posterior de como estas categorias operam na modelação de repertório de autoconhecimento, através da identificação de variáveis controladoras de alterações nos relatos verbais.

\section{Referências}

Banaco, R. A. \& Zamignani, D. R. (1999). Uma proposta de análise da modelagem de repertório clínico. Trabalho apresentado no Simpósio Metodologia para a Análise da Interação Terapêutica, VI Latini Dies, Sevilha, Espanha.

Barker, C., Pistrang, N. \& Elliot, R. (1994). Research methods in clinical and counseling psychology. Chichester: John Wiley \& Sons.

Campos, L. F. L. (1989). Supervisão clínica: Um instrumento de avaliação do desempenho clínico. Dissertação de Mestrado não-publicada, Pontifícia Universidade Católica de Campinas. Campinas, SP.

Campos, L. F. L. (1994). Supervisão em psicologia clínica: Critérios, condutas e modelos de supervisão. Tese de Doutorado não-publicada, Instituto de Psicologia da Universidade de São Paulo. São Paulo, SP.

De Rose, J. C. (1997). O relato verbal segundo a perspectiva da análise do comportamento: Contribuições conceituais e experimentais. Em R. A. Banaco (Org.), Sobre comportamento e cognição (Vol. 1, pp. 148-163). Santo André: Arbytes.

Drash, P. W. \& Tudor, R. M. (1991). A standard methodology for the analysis, recording, and control of verbal behavior. The Analysis of Verbal Behavior, 9, 49-60.

Edelstein, B. A. \& Brasted, W. S. (1991). Clinical training. Em M. Hersen, A. E. Kazdin \& A. S. Bellack (Org.), The clinical psychology handbook (2a ed). New York: Pergamon-Press (pp. 45-65) (2a ed). New York: Perganon Press.

Ellis, M. V., Ladany, N. Krengel, M. \& Schult, D. (1996). Clinical supervision research from 1981 to 1993: A methodological critique. Journal of Counseling Psychology, 43(1), 35-50.

Follette, W. C. \& Callaghan G. M. (1995). Do as I do not as I say: A behavioranalytic approach supervision. Professional Psychology: Research and Practice, 26, 413-421.

Greene, D. Mac \& Bry, B. H. (1991). A descriptive analysis of family discussions about everyday problems and decisions. The Analysis of Verbal Behavior, 9, 29-39. 
Leigland, S. (1996). An experimental analysis of ongoing verbal behavior: Reinforcement, verbal operants, and superstitious behavior. The Analysis of Verbal Behavior, 13, 79-104.

Robiner, W. N., Saltzman, S. R., Hoberman, H. M. \& Schirvar, J. A. (1997). Psychology supervisor's training, experiences, supervisory evaluation and self-related competence. The Clinical Supervisor, 16, (1), 117-143.

Skinner, B. F. (1969). Contingencies of reinforcement: A theoretical analysis. Englewood Cliffs, New Jersey: Prentice-Hall.
Watkins Jr., C. E. (1997). The ineffective psychotherapy supervisor: Some reflections about bad supervisors, poor process, and offensive outcomes. The Clinical Supervisor, 16, 163-179.

Recebido: 27/05/2002

$1^{a}$ revisão: 08/08/2002

Última revisão: 23/09/2002

Aceite final: 25/09/2002

Sobre a autora

Sandra Bernadete da Silva Moreira é Psicóloga, Mestre em Psicologia Experimental pela Pontifícia Universidade Católica de São Paulo. É Doutoranda no Programa de Pós-Graduação em Teoria e Pesquisa do Comportamento da Universidade Federal do Pará. É Professora do Departamento de Psicologia Clínica da Universidade Federal do Pará. 


\section{Anexo A}

\section{Categorias de Verbalizações do Supervisor}

CON - Concordância: verbalizações que denotam concordância com um relato ou uma interpretação feita pelo Terapeuta. Ex.: "Isso.".

COR - Corretivas. Supervisor corrige uma descrição feita pelo Terapeuta de eventos ocorridos na sessão. Ex.: "Isso aconteceu antes".

CRIT - Supervisor apresenta críticas ou desaprovação em relação ao comportamento do terapeuta. Ex.: "Você não analisou os antecedentes"; "Faltou você fažer a pergunta [P"; "Aquilo estava errado".

DCC - Descrições do comportamento do Cliente ocorrido na sessão. Ex.: "A primeira coisa que o cliente falou foi...".

DCT - Descrições do comportamento do Terapeuta ocorrido durante a sessão. Ex.: "Ai você falou para ele assim...".

DET - Solicitações de maiores detalhes ou que o Terapeuta continue seu relato. Tal categoria constitui-se de verbalizações mínimas do tipo "Hum" "Sel", cuja classificação se baseia na entonação de voz do supervisor.

DIS - Discordância. Supervisor expressa discordância com o relatado pelo terapeuta sobre o que ocorreu na sessão. Ex.: "Ele estava sim"; "Não foi verdade. Foi você quem provocou o comportamento dele".

DPAC - Supervisor descreve princípios da análise do comportamento e/ou distúrbios de comportamento. Ex.: "Quando o sujeito está em esquema de intervalo fixo, não havendo punição, ele vai manter a resposta durante muito tempo"; "No TOC, opensamento é intrusivo."

ELO - Elogios dirigidos ao comportamento do Terapeuta. "Isso que você fez foi ótimo"; "Você fez uma metáfora com o futebol que foi fantástica".

ENT - Verbalizações que expressam entendimento do relato de T. Ex.: "Sei"; "Entendi".

ESC - Solicitações de esclarecimentos, através de perguntas, após fala do Terapeuta. Ex.: "Por que?"; "O que houve?"

INTC - Supervisor interpreta e/ou analisa comportamentos do cliente ocorridos dentro ou fora da sessão; faz deduções a partir do relato do terapeuta e/ou do cliente. Ex.: "O cliente não está confiando em você ainda para falar da queixa".

INTS - Supervisor formula hipóteses ou interpreta eventos ocorridos na sessão. Ex.: "A sessão começon a ficar complicada quando você começou a querer identificar o que que era normal'.

INTT - Supervisor interpreta e/ou analisa comportamentos do terapeuta; explicações sobre o comportamento do terapeuta. Ex.: "Algumas perguntas que você faz são fechadas".

INV - Investigação: S. faz perguntas a T. sobre questões gerais da sessão. Ex.: "O que você achou da sessão?"

RCO - Supervisor estabelece relações entre o comportamento do terapeuta e do cliente. Ex.: "No momento em que ele dá uma resposta ..., você critica... e o efeito disso é ...".

REGE - Regras específicas; na forma imperativa. Supervisor fornece instruções ao terapeuta, descrevendo respostas que deveriam ser emitidas ou deverão ser emitidas em sessões posteriores, bem como suas prováveis conseqüências. P. ex.: "Você deve mudar suas perguntas"; "Faça essa pergunta para o cliente".

REGG - Regras gerais de atendimento, na $3^{\text {a }}$ pessoa. Supervisor fornece explicações sobre eventos de terapia, ou faz afirmações categóricas sobre a relação terapêutica de um modo geral. Ex.: "O cliente é soberano na sessão"; "O terapeuta tem que acreditar no que o cliente fala".

SER - Verbalizações que solicitam a T. que estabeleça relação entre eventos ocorridos na sessão. Ex.: "Que efeito isso teve sobre ele?" "O que você estava querendo saber quando fež essa pergunta?" 


\section{Anexo B}

\section{Categorias de Verbalizações do Terapeuta, nas sessões de supervisão:}

TAVS - Terapeuta interpreta e/ou avalia eventos ocorridos da sessão. Ex.: "Eu acho que isso foi um ponto positivo na sessão".

TCON - Verbalizações de concordância com um relato ou análise feita pelo Supervisor. Verbalizações mínimas ou repetições de verbalizações anteriores do supervisor, tais como: "Isso"; "É".

TDCC - Descrições do comportamento do cliente. Ex.: "Ele disse que era como assistir as Olimpiadas".

TDIS - Verbalizações de discordância com um relato ou análise feita pelo Supervisor. Ex.: "Não. Eu não aceitei quando ele falou isso"

TDPC - Descrições de seu próprio comportamento. Ex.: "Foi quando eu fiquei em silêncio."

TINC - Interpretações do comportamento do cliente durante a sessão ou fora dela. Ex.: "Eu tenho a impressão que isso é uma esquiva dele"; "Acho que a queixa não é dele".

TINT - Interpretações, julgamentos, justificativas, opiniões idéias, sobre seu próprio comportamento. Ex.: "O que eu fiz na sessão é muito semelhante ao que a mãe deve fažer, não é?"; "Eu fico dando alternativas pra ele porque ele não fala muito"; "Eu não estava entendendo o que estava acontecendo".

TRCO - Terapeuta descreve relações entre seu comportamento e o comportamento do cliente. Ex.: "Ele sorrin na hora em que eu comecei a conversar com ele sobre o que ele gosta."

TREG - Regras Específicas, na $1^{a}$ pessoa. Terapeuta descreve respostas que deveria ter emitido ou que emitirá em sessões posteriores. Ex.: "Vou pedir pra ele me ajudar".

TRGG - Regras gerais de atendimento, na $3^{a}$ pessoa. Terapeuta faz afirmações sobre a relação terapêutica de um modo geral. Ex.: "A pessoa se sente acolbida quando o outro está disposto a ouvi-la".

TSEC - Verbalizações que solicitavam esclarecimentos a um relato ou análise feita pelo Supervisor. Ex.: "O que era pra ter claro mesmo?"; "O problema é o modelo?"

TSOR - Verbalizações que solicitavam orientações ou sugestões de comportamentos futuros ao Supervisor. Ex.: "En queria discutir essa questão de apontar coisas negativas"

TTCO - Tomada de consciência: verbalizações de T. explicitando ser a primeira vez que percebe os controles de seu comportamento. Ex.: "Eu não prestei atenção nisso".; "Eu não vi isso". "Agora eu estou entendendo" 


\section{Anexo C}

\section{Categorias de Verbalizações do Terapeuta, nas sessões terapêuticas:}

TAVS - Terapeuta interpreta, analisa, aspectos da sessão terapêutica. Ex.: "A nossa sessão foi meio conturbada a semana passada."

TCON - Terapeuta concorda com o que o cliente relata. Ex.: "Isso é verdade."

TCRI - Terapeuta critica; desaprovação de verbalização anterior do cliente. Não foi observada a ocorrência desta categoria.

TCTN - Terapeuta sugere que o cliente dê continuidade ao que está relatando. Ex.: "Hum, bum."

TDCC - Terapeuta descreve o comportamento do cliente na sessão e fora dela. "Então o que você gosta é ir pra esporte mesmo."

TDIS - Terapeuta discorda do que o cliente relata. Não foi observada a ocorrência desta categoria.

TDPC - Terapeuta descreve seu próprio comportamento na sessão. Ex.: "Foi isso que eu te perguntei antes."

TELO - Terapeuta elogia; aprovação de verbalização anterior do cliente. Ex.: "Você é muito esperto."

TENT - Terapeuta expressa entendimento. Ex.: "Sei."; “Entendi”.

TFIN - Terapeuta fornece informações gerais para o cliente. Ex.: "Na semana que vem vai ter uma mudança no horário."

TICC - Terapeuta interpreta comportamento do cliente, relacionando-o com eventos do ambiente. Ex.: "Parece que você gosta bastante de futebol."

TPAR - Terapeuta parafraseia o cliente; repete verbalizações do cliente. Ex.: “... você me falou ... que você pensou numas coisas boas."

TRCO - Terapeuta descreve relações entre eventos. Ex.: “... pelo que eu estou entendendo, ..., ela falava algumas coisas pra vocêe e você não retrucava."

TREG - Terapeuta formula regras, sugere comportamentos futuros para o cliente. Ex.: "Pensa um pouco sobre isso e me fala na semana que vem."

TSDC - Terapeuta solicita descrições de comportamentos do cliente. Ex.: "O que você disse lá no seu grupo?"

TSDO - Terapeuta solicita descrições de comportamentos de outras pessoas ou de eventos do contexto do cliente. Ex.: "A sua tia também assiste os jogos na televisão?"

TSEC - Terapeuta solicita que o cliente esclareça ou forneça mais detalhes acerca de um relato do cliente. Ex.: "Como é essa dor?"

TSIN - Terapeuta solicita informações gerais ao cliente. Ex.: "A sua viz̨inha é casada?"

TSRE - Terapeuta solicita que o cliente estabeleça relações entre seus comportamentos e o de terceiros ou outros eventos de seu contexto. Ex.: "Por que você não gosta de ir a excursões da escola?" 


\section{Anexo D}

\section{Categorias de Verbalizações do Cliente}

CCON - Cliente concorda com verbalização anterior do Terapeuta. Ex.: "É. Me interesso sim ..."

CDCO - Cliente descreve o comportamento de outras pessoas ou eventos. Ex.: "Minha mãe me liga todo dia."

CDIS - Cliente discorda com verbalização anterior do Terapeuta. Ex.: "Não. Isso dai eu não curto, não."

CDPC - Cliente descreve seu próprio comportamento. Ex.: "Eu achei bonito aquele jogo."

CDRE - Cliente descreve relações entre seu comportamento e o de outras pessoas ou eventos. Ex.: "Nós não conversamos nada de importante."

CENT - Cliente manifesta entendimento do relato anterior do Terapeuta. Ex.: "Sei."; "Hum, hum."

CINC - Cliente interpreta, julga, analisa, dá opiniões, idéias, sobre seu próprio comportamento. Ex.: "Eu não respondo pra ela porque eu já sei o que vai dar."

CINF - Cliente fornece informações gerais ao Terapeuta, não específicas de seu comportamento. Ex.: "Esse time não ganba nada."

CINP - Cliente interpreta, julga, analisa, dá opiniões, idéias, sobre o comportamento de outras pessoas ou eventos relacionados ao seu contexto. Ex.: "É arriscado sair na rua porque pode ser assaltado."

CINS - Cliente interpreta, analisa, julga, dá opiniões, idéias, sobre o comportamento do terapeuta e de aspectos da relação terapêutica. Ex.: "Esse assunto começou com o caso da outra psicóloga."

CREG - Cliente explicita ou sugere comportamentos futuros para si próprio. Ex.: "Preciso buscar alguma coisa."

CSDE - Cliente solicita mais detalhes ao Terapeuta. Ex.: "Não gostei do que?"

CSEC - Cliente solicita esclarecimentos ao Terapeuta. Ex.: "Que duas coisas?"

CSIN - Cliente solicita informações gerais ao Terapeuta. Não foi observada a ocorrência desta categoria. 